\title{
Oestrogen production by the preimplantation donkey conceptus compared with that of the horse and the effect of between-species embryo transfer
}

\author{
R. B. Heap ${ }^{1}$, M. H. Hamon ${ }^{1}$ and W. R. Allen ${ }^{2}$ \\ ${ }^{1}$ AFRC Institute of Animal Physiology and Genetics Research, Babraham, Cambridge CB2 4AT, \\ UK; and ${ }^{2}$ Thoroughbred Breeders' Association Equine Fertility Unit, Mertoun Paddocks, \\ Woodditton Road, Newmarket, Suffolk, CB8 9BH, UK
}

\begin{abstract}
Summary. Aromatase distribution in membranes of preimplantation horse and donkey conceptuses was compared by measuring the incorporation of $\left[{ }^{3} \mathrm{H}\right]$ androstenedione into oestrone and oestradiol-17 $\beta$. In the donkey conceptus, aromatase activity was similar in all the tissues examined (yolk sac, chorionic girdle and allantochorion), whereas in the horse it was generally lower and showed the relationship chorionic girdle $>$ yolk sac $>$ allantochorion. A higher proportion of labelled precursor was incorporated into oestradiol- $17 \beta$ by extra-embryonic tissues of the donkey compared with those of the horse. In contrast to previous results, aromatase in the chorionic girdle did not decline progressively before its migration into the endometrium on Day 36 to form the endometrial cups. The chorionic girdle of a donkey conceptus carried in the uterus of a mare failed to invade the surrogate horse endometrium and aromatase activity was still high in this tissue at Day 42 . Aromatase distribution in 2 transferred donkey-in-horse conceptuses resembled that of the fetal, rather than the maternal, genotype indicating a lack of effect of the maternal environment.
\end{abstract}

Keywords: oestrogens; conceptus; embryo transfer; donkey

\section{Introduction}

In a previous study we reported that the capability of the preimplantation horse conceptus to synthesize oestrogens resembles that of the pig conceptus at comparable stages of gestation (Heap et al., 1982). In horses and pigs, maternal recognition of pregnancy occurs at Days 11 and 14-16 after ovulation, respectively (Dhindsa \& Dziuk, 1968; Hershman \& Douglas, 1979). Definitive attachment or implantation has been identified at Days 18 and 42, respectively, and placentation in both species is epitheliochorial and noninvasive, although cells from the annulate chorionic girdle in equids invade the maternal endometrium at Days 36-38 to form transient gonadotrophinsecreting endometrial cups (Fig. la; Allen et al., 1973). The results of the earlier study showed that aromatase activity in the extra-embryonic membranes of the horse conceptus is highest in the chorionic girdle $>$ trilaminar omphalopleure (allantochorion) $>$ bilaminar omphalopleure (choriovitelline membrane) (Heap et al., 1982) and this study has now been extended to examine another equine species, the donkey.

The question of whether aromatase activity is influenced by the maternal uterine environment was addressed by use of a transferred donkey-in-mare pregnancy. A feature of this extraspecific pregnancy, but not the reciprocal horse-in-donkey pregnancy or other between-species equine pregnancies, is the complete failure of the donkey chorionic girdle to invade the recipient horse endometrium at the expected time of Day 36 (Allen et al., 1987). This model of extraspecific pregnancy was therefore used to study aromatase in the persisting chorionic girdle by the transfer of 


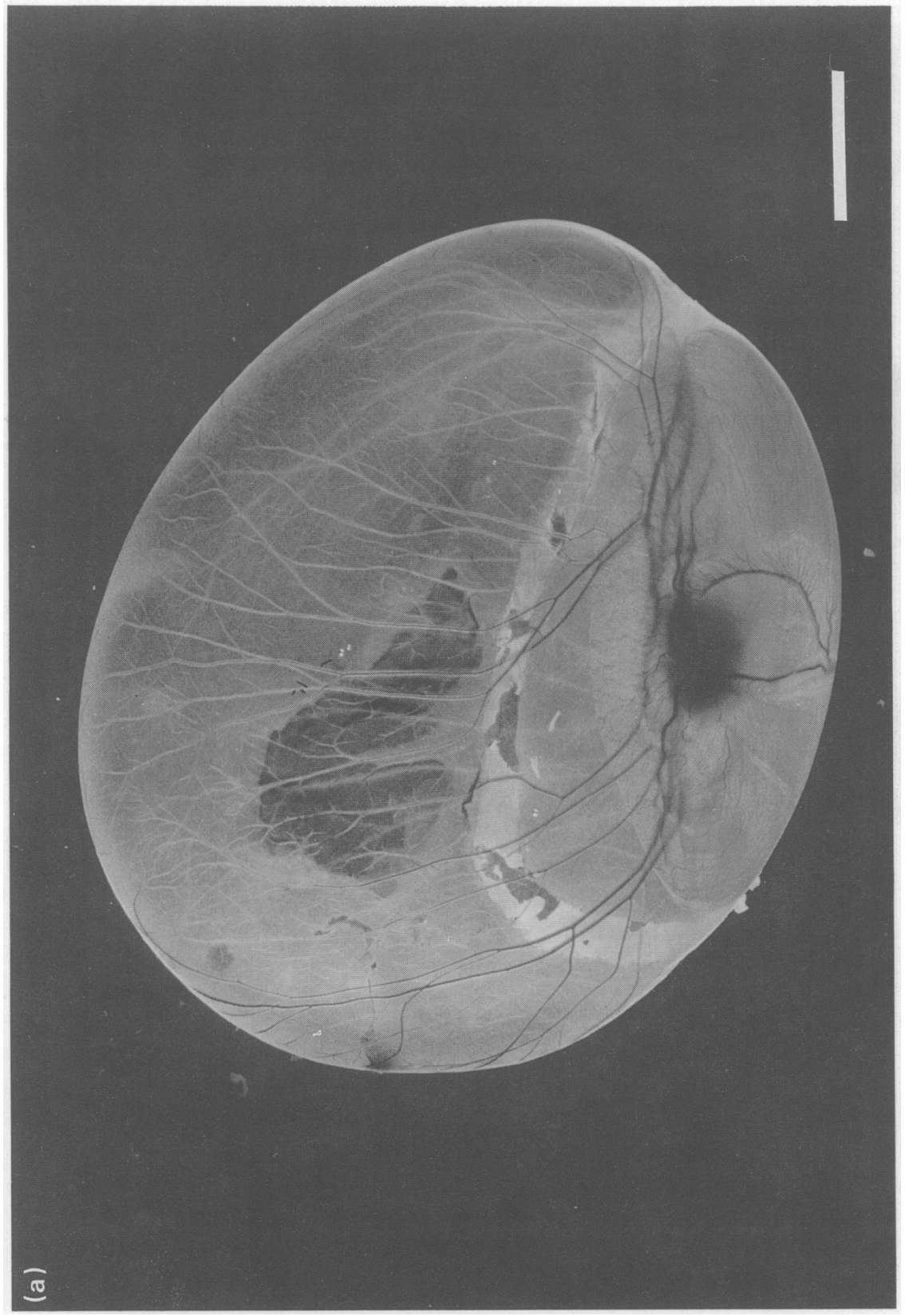




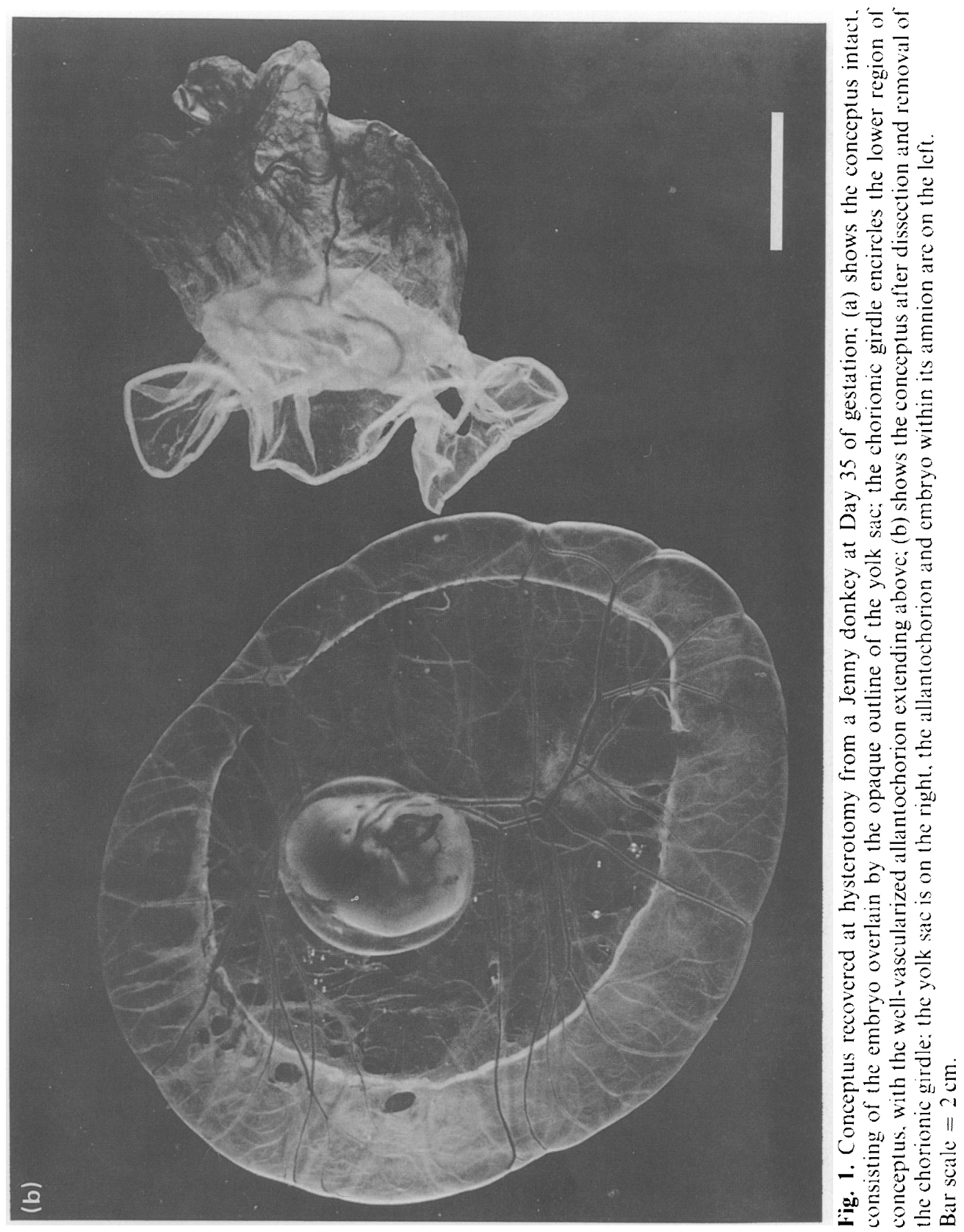


Day-7 donkey embryos into the uteri of unmated recipient mares with subsequent recovery of one conceptus at Day 36 and one at Day 42.

\title{
Materials and Methods
}

\begin{abstract}
Animals. Intact conceptuses were recovered at hysterotomy under general anaesthesia from 10 Jenny donkeys and 9 Welsh Pony mares between Days 30 and 43 after ovulation. The conceptus was placed in a bath of sterile phosphatebuffered saline and dissected with fine instruments to separate yolk sac, allantochorion and chorionic girdle tissues (Fig. 1). Embryos recovered from 2 Jenny donkeys on Day 7 were transferred surgically into the uteri of synchronized recipient mares as described by Allen (1982).

Determination of aromatase activity. After dissecting the various tissues, they were finely minced with scissors in cold sterile Medium 199 (Flow Laboratories, Irvine, UK) and weighed. Portions of known wet weight were placed in Erlenmeyer flasks containing $5 \mathrm{ml}$ Medium 199 and $\left[1,2,6,7-{ }^{3} \mathrm{H}\right]$ androstenedione $(98 \mathrm{Ci} \mathrm{TBq} / \mathrm{mmol}$ : Amersham International, UK). Representative portions of tissue were fixed in $10 \%$ formol saline or Bouin's solution for histological examination.

The total amount of tissue available from each conceptus varied greatly. The portions used for incubations were kept within $190-300 \mathrm{mg}$ for yolk sac, $180-300 \mathrm{mg}$ for allantochorion and $28-60 \mathrm{mg}$ for chorionic girdle. All incubations were carried out with a constant ratio of wet weight of tissue to amount of radiolabelled precursor (100 mg tissue/ $15.8 \mathrm{pmol}$ or $1.7 \mu \mathrm{Ci}\left[{ }^{3} \mathrm{H}\right]$ androstenedione). After incubation, radiolabelled phenolic compounds formed from androstenedione were separated from aqueous soluble compounds by solvent partition, and labelled oestrone and oestradiol- $17 \beta$ were identified in the phenolic fraction by thin-layer chromatography and recrystallization as described by Heap et al. (1982). Aromatase was expressed as the percentage incorporation of labelled precursor into phenolic compounds, oestrone and oestradiol-17 $\beta$. Individual values were converted to natural logarithmic values for statistical analysis by multivariate analysis.
\end{abstract}

\section{Results}

\section{Donkey and horse conceptuses}

The results showed that yolk sac, chorionic girdle and allantochorion all possessed aromatase between Days 30 and 43 after ovulation in donkey and horse conceptuses (Table 1).

In yolk sac, the incorporation of labelled androstenedione into phenolic compounds remained constant with increasing gestational age in donkey tissues, but it increased slightly in horse tissues from Day 30 to Day 43 . Oestrone and oestradiol- $17 \beta$ together accounted for 86 and $54 \%$ of the total amount of radioactivity recovered in the phenolic fraction of the donkey and horse yolk sac tissues, respectively. The amount of radiolabelled oestrone or oestradiol-17 $\beta$ formed from $\left[{ }^{3} \mathrm{H}\right]$ androstenedione was significantly greater in the donkey than in the horse $(P<0.001)$. The ratio of oestrone:oestradiol-17 $\beta$, however, was not significantly different in the two species (donkey $1 \cdot 14$, horse $1 \cdot 75$; Table 1 ).

Chorionic girdle samples were available only up to Day 35 , before migration of this tissue into the endometrium. There was no evidence for any increase in the formation of phenolic compounds during the period of study in either species and in the horse the total amount of phenolic compounds formed did not differ significantly from that measured in the yolk sac incubations. In donkey, however, significantly more phenolic compounds were formed than in the horse. Oestrone and oestradiol- $17 \beta$ together accounted for 93 and $72 \%$ of the total amount of radioactivity in the phenolic fraction in donkey and horse tissue incubations, respectively. More labelled oestradiol$17 \beta$ was recovered from this tissue than from yolk sac incubations in both species, and the ratio of oestrone:oestradiol-17 $\beta$ was significantly less than unity (donkey 0.50 , horse 0.43 ). There was no progressive fall in aromatase activity up to the day before invasion of the chorionic girdle into the maternal endometrium in either species (Table 2).

In the allantochorion, there was no increase in the amount of phenolic compounds produced over the period of study in either species. In the donkey, mean values for the amount of oestrone and oestradiol-17 $\beta$ were within the range found for yolk sac and chorionic girdle, but, in the horse, significantly less of these compounds was produced. Oestrone and oestradiol-17 $\beta$ together accounted for, respectively, 84 and $20 \%$ of the total amount of radioactivity found in the phenolic 
Table 1. Aromatase in extra-embryonic membranes of donkey (D) and horse (H) conceptuses recovered between 30 and 43 days after ovulation. Aromatase is expressed as the percentage incorporation of $\left[{ }^{3} \mathrm{H}\right]$ androstenedione into phenolic compounds, oestrone and oestradiol-17 $\beta$. Results are presented as natural logarithmic (mean $\pm \mathrm{SEM}$, in brackets) and arithmetic mean values after back-transformation

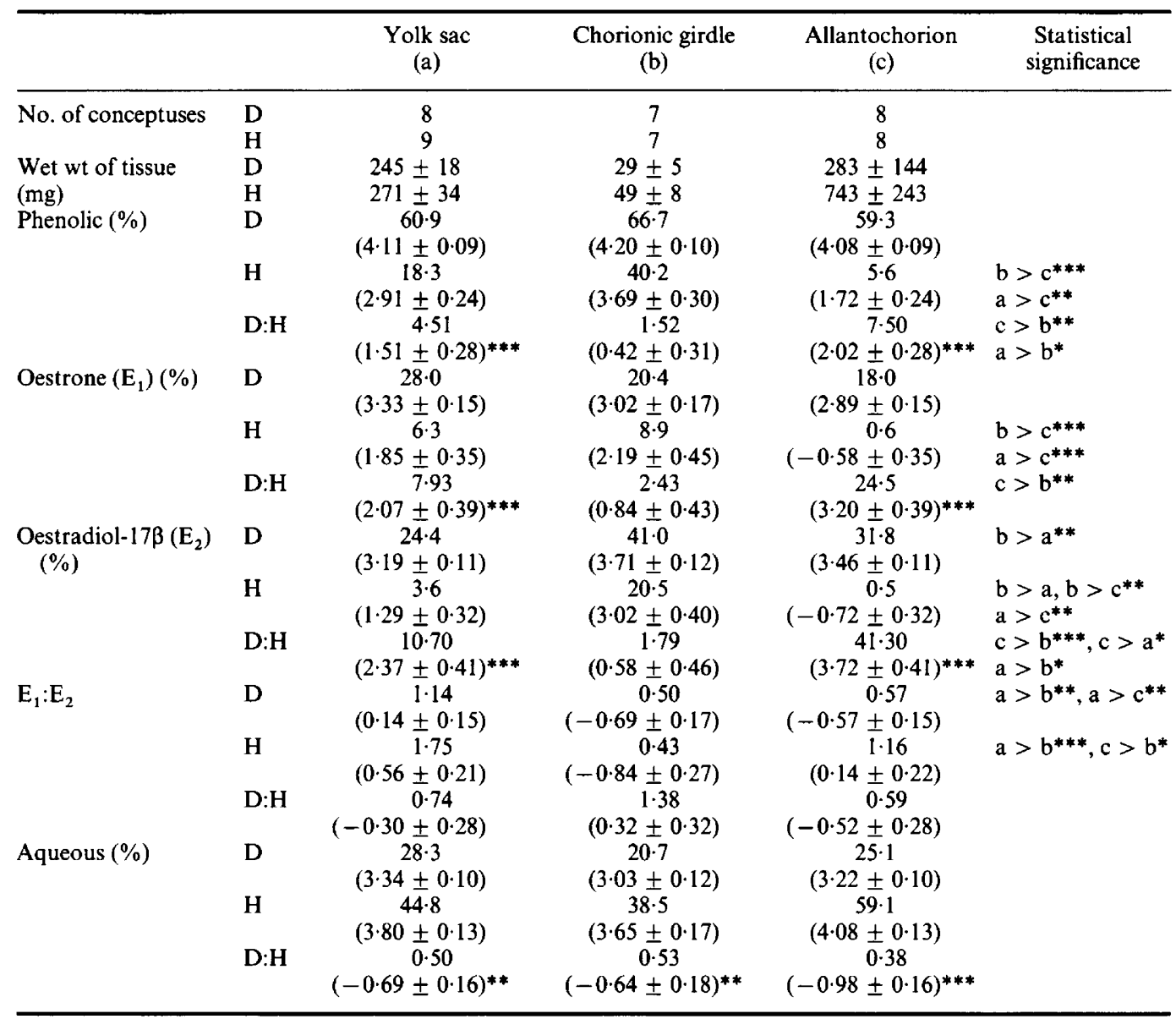

${ }^{*} P<0.05,{ }^{* *} P<0.01,{ }^{* * *} P<0.001 ; \mathrm{D}: \mathrm{H}$ values significantly different from unity.

fraction in the donkey and horse, indicating the presence of other oestrogens formed during incubations with horse allantochorion. The ratio of oestrone:oestradiol-17 $\beta$ was lower after incubation of donkey $(0 \cdot 57)$ than of horse $(1 \cdot 16)$ allantochorion, but the difference was not statistically significant.

A similar quantity of aqueous-soluble compounds was formed in all three tissues, but significantly less was produced in incubations of donkey than of horse tissues (Table 1). Analysis of these compounds showed that conjugated forms of oestrone and oestradiol-17 $\beta$ were present, but the maximum concentration was $<10 \%$ of the unconjugated steroid and in most cases much lower.

\section{Extraspecific transfers}

The results showed that, at Days 36 and 42, the amounts of phenolic compounds formed and the quantities of oestrone and oestradiol-17 $\beta$ resembled those found in the nontransferred (intraspecific) donkey conceptus, rather than in the horse conceptus (cf. Tables 1 and 3). Oestrone and oestradiol-17 $\beta$ together accounted for 82 and $83 \%$ ( 2 animals) of the total amount of radiolabelled 
Table 2. Aromatase in the chorionic girdle of donkey (D) and horse $(\mathrm{H})$ conceptuses during the period before its migration into the maternal endometrium at Day 36. Results were obtained for individual animals at each day of pregnancy and aromatase activity was expressed as percentage incorporation of $\left[{ }^{3} \mathrm{H}\right]$ androstenedione into oestrone and oestradiol-17 $\beta$. Wet weight of tissue incubated was $29 \pm 5$ and $40 \pm 5 \mathrm{mg}$ for samples from donkey and horse conceptuses, respectively

\begin{tabular}{|c|c|c|c|c|c|c|}
\hline \multirow{3}{*}{$\begin{array}{l}\text { Day of } \\
\text { pregnancy }\end{array}$} & \multicolumn{6}{|c|}{$\%$ Incorporation of $\left[{ }^{3} \mathrm{H}\right]$ androstenedione } \\
\hline & \multicolumn{2}{|c|}{ Oestrone $\left(E_{1}\right)$} & \multicolumn{2}{|c|}{ Oestradiol-17ß $\left(E_{2}\right)$} & \multicolumn{2}{|c|}{$E_{1}: E_{2}$} \\
\hline & D & $\mathbf{H}$ & D & $\mathbf{H}$ & D & $\mathrm{H}$ \\
\hline 30 & $20 \cdot 4$ & $9 \cdot 0$ & $61 \cdot 6$ & $30 \cdot 4$ & 0.33 & 0.29 \\
\hline 32 & $27 \cdot 6$ & $10 \cdot 9$ & $46 \cdot 1$ & $18 \cdot 1$ & 0.60 & 0.60 \\
\hline 33 & $17 \cdot 1$ & $5 \cdot 4$ & $30 \cdot 6$ & $16 \cdot 6$ & 0.56 & $0 \cdot 32$ \\
\hline 34 & $18 \cdot 1$ & $9 \cdot 5$ & $32 \cdot 6$ & $30 \cdot 5$ & 0.56 & $0 \cdot 31$ \\
\hline 35 & - & $11 \cdot 2$ & - & $13 \cdot 1$ & - & 0.86 \\
\hline
\end{tabular}

Table 3. Aromatase in the yolk sac, chorionic girdle and allantochorion of 2 transferred donkey conceptuses recovered from the uteri of recipient mares on Days 36 and 42 after ovulation. Tissues were separated before incubation in the presence of $\left[{ }^{3} \mathrm{H}\right]$ androstenedione. Results are expressed as the percentage incorporation of labelled precursor into phenolic compounds, oestrone, oestradiol-17 $\beta$ and aqueous-soluble compounds

\begin{tabular}{lcccccc}
\hline & \multicolumn{2}{c}{ Yolk sac } & \multicolumn{2}{c}{ Chorionic girdle } & \multicolumn{2}{c}{ Allantochorion } \\
\hline Age of conceptus (days) & 36 & 42 & 36 & 42 & 36 & 42 \\
Wet wt of tissue incubated $(\mathrm{mg})$ & 270 & 140 & 40 & 10 & 300 & 300 \\
Phenolic $(\%)$ & $49 \cdot 7$ & $53 \cdot 7$ & $75 \cdot 9$ & $66 \cdot 2$ & $49 \cdot 7$ & $53 \cdot 7$ \\
Oestrone $\left(\mathrm{E}_{1}\right)(\%)$ & $24 \cdot 8$ & $23 \cdot 9$ & $14 \cdot 7$ & $19 \cdot 8$ & $5 \cdot 5$ & $7 \cdot 4$ \\
Oestradiol-17\% $\left(\mathrm{E}_{2}\right)(\%)$ & $16 \cdot 2$ & $20 \cdot 8$ & $69 \cdot 7$ & $43 \cdot 7$ & $15 \cdot 5$ & $25 \cdot 2$ \\
$\mathrm{E}_{1}: \mathrm{E}_{2}$ & $1 \cdot 53$ & $1 \cdot 14$ & $0 \cdot 21$ & $0 \cdot 45$ & 0.53 & $0 \cdot 29$ \\
Aqueous $(\%)$ & $23 \cdot 4$ & $17 \cdot 0$ & $24 \cdot 3$ & $13 \cdot 7$ & $23 \cdot 4$ & $17 \cdot 0$ \\
\hline
\end{tabular}

phenolic compounds in yolk sac, 111 and $96 \%$ in chorionic girdle and 42 and $61 \%$ in the allantochorion. The figures for allantochorionic tissue were intermediate between those for the donkey and horse conceptuses. Persistence of the chorionic girdle beyond its normal time of migration at Day 36 was not associated with any loss of aromatase activity (Table 3).

\section{Discussion}

The results of this study showed that the donkey conceptus, as well as the horse conceptus, has the enzymatic capability to produce substantial amounts of oestrogens before the time of implantation. Moreover, as demonstrated by two extraspecific donkey-in-horse pregnancies, fetal genotype, rather than maternal uterine environment, seemed to control the development and expression of this enzyme capacity in the extra-embryonic membranes.

A feature of the results is the high aromatase activity in the donkey conceptus, as indicated by the conversion of $\left[{ }^{3} \mathrm{H}\right]$ androstenedione into oestrogens. The values obtained were equal to, and in some instances exceeded, those in either horse or pig conceptuses recovered before implantation. Oestrone and oestradiol-17 $\beta$ accounted for most of the phenolic compounds formed in the donkey membrane incubations and this was also true in the horse conceptus, except that, in yolk sac and 
allantochorion tissues, only 54 and $20 \%$, respectively, could be attributed to these two oestrogens. The possibility exists, therefore, that, although aromatase activity appears to be lower in the allantochorion than the yolk sac of the horse conceptus, oestrogens other than oestrone and oestradiol-17 $\beta$ may be produced in the allantochorion. In this respect, it is notable that catechol oestradiol induces implantation in mice (Hoversland et al., 1982) and that catechol oestrogens stimulate prostaglandin production in preimplantation rabbit blastocysts and endometrium (Pakrasi et al., 1983). However, there is no definitive evidence for the synthesis of these compounds by preimplantation conceptuses.

The present findings confirm our earlier observations that aromatase in horses is most prominent in chorionic girdle $>$ yolk sac $>$ allantochorion (Heap et al., 1982). In donkeys, on the other hand, aromatase is similar in all three extra-embryonic membranes. With respect to the chorionic girdle, there was an indication in our previous experiments that the conversion of labelled androstenedione into oestrogens declined as the time of migration approached. This aspect was reexamined in the present study, using weights of tissues kept within close limits to minimize the effect of decreasing amounts of tissue around the time of migration. The results showed no evidence for the decline in aromatase before migration suggested previously. Production of phenolic compounds, and of oestrone and oestradiol-17 $\beta$ from labelled precursor, was also maintained in the donkey-in-horse chorionic girdle. It seems unlikely that the failure of transferred donkey chorionic girdle to become invasive is related to the persistence of aromatase activity, since chorionic girdle migration in normal intraspecific pregnancies is not preceded by a significant decline in this enzyme. The biological significance of such high aromatase activity in the preimplantation conceptus of species such as donkey, horse and pig remains elusive, but it is clear from the present experiments that it is unrelated to the failure of the donkey-in-horse pregnancy model.

This study was supported by the Agricultural and Food Research Council, the Horserace Betting Levy Board and the Thoroughbred Breeders' Association. We are grateful to M. S. Boyle, MA, Vet MB, MRCVS for assistance with the establishment and recovery of equine conceptuses.

\section{References}

Allen, W.R. (1982) Immunological aspects of the endometrial cup reaction and the effects of xenogenic pregnancy in horses and donkeys. J. Reprod. Fert., Suppl. 31, 57-94.

Allen, W.R., Hamilton, D.W. \& Moor, R.M. (1973) The origin of equine endometrial cups. II. Invasion of the endometrium by trophoblast. Anat. Rec. 177, 485-502.

Allen, W.R., Kydd, J. H., Boyle, M.S. \& Antczak, D.F. (1987) Extraspecific donkey-in-horse pregnancy as a model of early fetal death. J. Reprod. Fert., Suppl. 35, 197-209.

Dhindsa, D.S. \& Dziuk, P.J. (1968) Effect on pregnancy in the pig after killing embryos or fetuses in one uterine horn in early gestation. J. Anim. Sci. 27, $122-126$.
Heap, R.B., Hamon, M. \& Allen, W.R. (1982) Studies on oestrogen synthesis by the preimplantation equine conceptus. J. Reprod. Fert., Suppl. 32, 343-352.

Hershman, E. \& Douglas, R.H. (1979) The critical period for maternal recognition of pregnancy in Pony mares. J. Reprod. Fert., Suppl. 27, 395 401.

Hoversland, R.C., Dey, S.K. \& Johnson, D.C. (1982) Catechol estradiol induced implantation in the mare. Life Sci. 30, 1801-1804.

Pakrasi, P.L. \& Dey, S.K. (1983) Catechol estrogens stimulate synthesis of prostaglandins in the preimplantation rabbit blastocysts and endometrium. Biol. Reprod. 29, 347-354.

Received 21 September 1990 